\begin{tabular}{|c|c|c|}
\hline $\begin{array}{l}\text { OPEN ACCESS } \\
\text { Vol. } 1 \text { No. 2: } 32-37 \\
\text { Tahun 2018 } \\
\text { Artikel penelitian 圈 }\end{array}$ & $\begin{array}{l}\text { Durrnal Alkuditilestari } \\
\text { E-ISSN: 2598-8204 } \\
\text { https://ojs.umrah.ac.id/index.php/akuatiklestari } \\
\text { DOI : https://doi.org/10.31629/.v1i2.2294 }\end{array}$ & $\therefore$ \\
\hline
\end{tabular}

\title{
Copepoda sebagai Indikator Keberadaan Kuda Laut (Hippocampus sp.) di Perairan Desa Sebong Pereh, Bintan
}

\author{
Copepoda an Indicator of the Existence of Sea Horse (Hippocampus sp.) in Waters of Sebong Pereh \\ Village, Bintan
}

\section{Siti Hidayani1 ${ }^{\bowtie}$, Tri Apriadi' ${ }^{1}$, Dedy Kurniawan ${ }^{1}$}

${ }^{1}$ Manajemen Sumberdaya Perairan, Fakultas Ilmu Kelautan dan Perikanan, Universitas Maritim Raja Ali Haji, Tanjungpinang, Indonesia 29111

\section{$\square$ Info Artikel:}

Diterima: 1 Mei 2018

Revisi: 5 Mei 2018

Disetujui: 17 Mei 2018

Dipublikasi: 30 Mei 2018

[a] Keyword:

Copepoda, Kuda Laut, Hippocampus sp., Bintan

$\triangle$ Penulis Korespondensi:

Siti Hidayani

Manajemen Sumberdaya Perairan, Fakultas IImu Kelautan dan Perikanan, Universitas Maritim Raja Ali Haji, Tanjungpinang, Indonesia 29111 Email: sitihidayanie@gmail.com

\begin{abstract}
ABSTRAK. Penelitian mengenai hubungan Copepoda sebagai indikator keberadaan Hippocampus sp. telah dilakukan di Perairan Desa Sebong Pereh. Tujuan penelitian ini adalah untuk melihat hubungan keberadaan Copepoda sebagai indikator keberadaan Hippocampus sp. di Perairan Desa Sebong Pereh. Penelitian ini dilakukan dengan metode random sampling sebanyak 31 titik menggunakan transek $5 \times 5$ m untuk kepadatan Hippocampus sp. dan untuk mengambil sampel Copepoda menggunakan planktonnet secara statis sebanyak $100 \mathrm{~L}$. Hasil penelitian ditemukan tiga spesies Hippocampus sp. yaitu dengan nilai kepadatan H. comes $670 \mathrm{ind} / \mathrm{Ha}, \mathrm{H}$. kuda $530 \mathrm{ind} / \mathrm{Ha}$, dan H. mohnikei 400 ind/Ha. Kelimpahan Copepoda ditemukan 9 spesies dari 3 ordo yaitu dengan kelimpahan pada Naupli sp. 3380 ind $/ \mathrm{m}^{3}$, Acartia sp. $1450 \mathrm{ind} / \mathrm{m}^{3}$, Acrocalanus sp. $480 \mathrm{ind} / \mathrm{m}^{3}$, Lucicutia sp. $6100 \mathrm{ind} / \mathrm{m}^{3}$, Calanus sp. $1450 \mathrm{ind} / \mathrm{m}^{3}$, Oithona sp. $680 \mathrm{ind} / \mathrm{m}^{3}$, Tisbe sp. $4450 \mathrm{ind} / \mathrm{m}^{3}$, dan Microsetella sp. $870 \mathrm{ind} / \mathrm{m}^{3}$. Berdasarkan analisis PCA nilai kelimpahan Copepoda tidak memiliki hubungan terhadap kepadatan kuda laut di Perairan Desa Sebong Pereh. Hal ini menunjukkan Copepoda tidak bisa dijadikan sebenuhnya sebagai indikator keberadaan kuda laut di Perairan Desa Sebong Pereh.
\end{abstract}

\begin{abstract}
Research on the relationship of Copepoda as an indicator of the presence of Hippocampus sp. has been carried out in the waters of Sebong Pereh Village. The purpose of this study was to see the existence of Copepoda as an indicator of the presence of Hippocampus sp. in the waters of Sebong Pereh Village. This research was conducted with a random sampling method of 31 points using a $5 \times 5 \mathrm{~m}$ transect for the density of Hippocampus sp. and static sampling of Copepoda using planktonnet as much as $100 \mathrm{~L}$. The results of the study found three species of Hippocampus sp. that was with the density value of $\mathrm{H}$. comes $670 \mathrm{ind} / \mathrm{Ha}, \mathrm{H}$. horse 530 ind/Ha, and $\mathrm{H}$. mohnikei $400 \mathrm{ind} / \mathrm{Ha}$. Copepod abundance was found in 9 species from 3 orders namely abundance in Naupli sp. $3380 \mathrm{ind} / \mathrm{m}^{3}$, Acartia sp. $1450 \mathrm{ind} / \mathrm{m}^{3}$, Acrocalanus sp. 480 ind $/ \mathrm{m}^{3}$, Lucicutia sp. $6100 \mathrm{ind} / \mathrm{m}^{3}$, Calanus sp. $1450 \mathrm{ind} / \mathrm{m}^{3}$, Oithona sp. $680 \mathrm{ind} / \mathrm{m}^{3}$, Tisbe sp. 4450 ind $/ \mathrm{m}^{3}$ and Microsetella sp. $870 \mathrm{ind} / \mathrm{m}^{3}$. Based on PCA analysis, the value of Copepoda abundance has no relationship with the density of seahorses in the waters of Sebong Pereh Village. This shows that Copepoda cannot be used as an indicator of the presence of seahorses in the waters of Sebong Pereh Village.
\end{abstract}

How to cite this article:

Hidayani, S., Apriadi, T., \& Kurniawan, D. (2018). Copepoda sebagai Indikator Keberadaan Kuda Laut (Hippocampus sp.) di Perairan Desa Sebong Pereh, Bintan. 1(2): 32-37. https://doi.org/10.31629/.v1i2.2294

\section{PENDAHULUAN}

Perairan Kepulauan Riau merupakan perairan yang memiliki banyak sumberdaya salah satu nya yaitu kuda laut, dimana kuda laut dikenal dengan sebutan "ondok-ondok". Kebutuhan akan kuda laut kering masih tergantung dari hasil tangkapan nelayan di alam. Tangkapan kuda laut dilakukan pada saat perairan surut dan menggunakan alat tangkap sondong. Penangkapan kuda laut biasanya dilakukan pada bulan Maret hingga bulan Agustus, dimana pada bulan tersebut merupakan bulan benih bagi kuda laut (Asmanelli \& Andreas, 1993).

Pada Perairan Desa Sebong Pereh sudah pernah dilakukan penelitian mengenai Kuda laut (Hippocampus sp.) Pada penelitian pertama oleh Fianda et al. (2015) dilakukan penelitian mengenai identifikasi dan inventarisasi jenis Kuda laut (Hippocampus sp.). Kemudian penelitian Rabiansyah et al. (2015) mengenai studi ekologi kuda laut (Hippocampus sp.). 
Pada ekosistem perairan, banyak biota yang ditemukan mulai dari biota primer yang berfungsi sebagai produsen utama sampai ke konsumen tingkat tertinggi di perairan (Kurniawan, 2014). Salah satu biota yang memiliki fungsi penting bagi kehidupan di perairan yaitu zooplankton. Pada perairan, zooplankton memiliki cara hidup yang melayang dan mengapung mengikuti arus dan juga mampu hidup pada perairan yang dalam. Dari aspek lingkungan global plankton pun tidak kalah penting, hampir semua hewan yang mampu berenang bebas (nekton) dan benthos memakan zooplankton, dan ada yang mengawali hidupnya sebagai zooplankton ketika masih berupa telur dan larva (Nontji, 2008).

Kuda laut atau Hippocampus sp. merupakan salah satu biota laut yang salah satu sumber makanannya berupa zooplankton yaitu Copepoda. Pada penelitian Rabiansyah et al. (2015) pengamatan yang dilakukan pada isi organ pencernaan (usus) dan di perairan ditemukan zooplankton yang teridentifikasi yaitu dari kelas Copepoda. Pada penelitian Redjeki (2007), dilakukan pemberian pakan Copepoda kepada Hippocampus sp. Secara umum, kuda laut adalah karnivora yang memangsa zooplankton seperti Copepoda dari sudut ekologi, hanya satu golongan dari zooplankton yang sangat penting artinya, yaitu dari subklas copepoda (klas Crustacea, Filum Arthropoda). Copepoda adalah crustacean haloplanktonik yang berukuran kecil yang mendominasi zooplankton di semua samudra dan laut. Hewan kecil ini sangat penting artinya bagi ekonomi ekosistem-ekosistem bahari yang merupakan herbivora primer dalam laut. Dengan demikian Copepoda berperan sebagai mata rantai yang amat penting antara produksi primer fitoplankton dengan karnivora besar dan kecil (Nybakken, 1988). Berdasarkan hal tersebut, maka perlu dilakukannya penelitian untuk melihat hubungan keberadaan Copepoda sebagai indikator keberadaan Hippocampus sp. di Perairan Desa Sebong Pereh, Bintan.

\section{BAHAN DAN METODE}

\subsection{Waktu dan tempat}

Penelitian ini dilaksanakan pada bulan Januari - Maret 2018, bertempat di Perairan Desa Sebong Pereh, Kecamatan Teluk Sebong, Kabupaten Bintan, Provinsi Kepulauan Riau. Lokasi penelitian dapat dilihat pada Gambar 1.

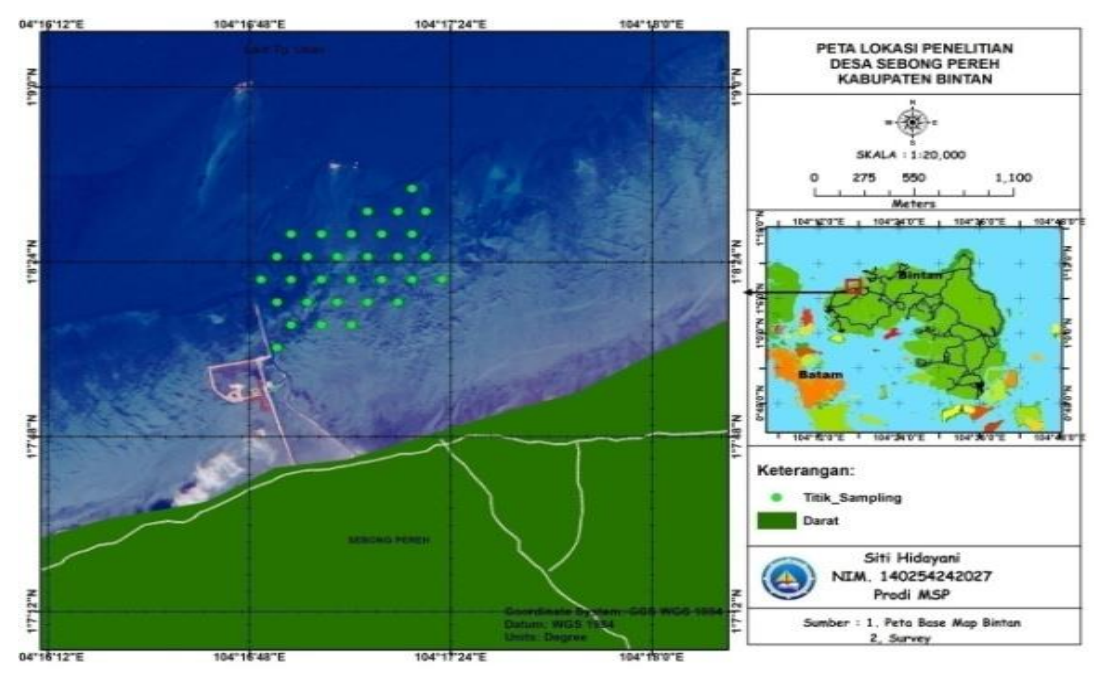

Gambar 1. Peta lokasi penelitian

\subsection{Alat dan Bahan}

Alat dan bahan yang digunakan dalam penelitian ini antara lain multitester untuk mengukur suhu, dan DO; pH meter untuk mengukur $\mathrm{pH}$, echosounder untuk mengukur kedalaman perairan; refraktometer untuk mengukur salinitas; botol sampel sebagai wadah sampel air; SRC (sedgewick rafter counting chamber) untuk menghitung jumlah plankton; Ember $10 \mathrm{~L}$ untuk mengambil sampel air; GPS untuk menentukan titik koordinat lokasi sampling; planktonnet untuk mengambil sampel plankton; ice box untuk membawa sampel ke laboratorium; Mikroskop Optik untuk mengamati plankton; Lugol $10 \%$ untuk mengawetkan plankton; dan aquades untuk membersihkan peralatan.

\subsection{Prosedur Penelitian}

Metode penelitian yang digunakan dalam penentuan lokasi sampling untuk pengambilan data kuda laut dan copepoda menggunakan metode Random Sampling dengan bantuan software VSP (Visual Sampel Plan) dengan citra Quick Bird. Titik pengamatan ditetapkan sebanyak 31 titik pengamatan pada lokasi penangkapan kuda laut di Perairan Desa Sebong Pereh, Kabupaten Bintan.

\subsection{Teknik Pengumpulan Data}

\subsubsection{Pengambilan Sampel Air}

Sampel air diambil untuk mendapatkan sampel Copepoda. Prosedur pertama dalam pengambilan data dan sampel Copepoda yaitu pengukuran parameter fisika dan kimia. Parameter yang diamati disajikan pada Tabel 1. 
Tabel 1. Parameter yang diamati dalam penelitian

\begin{tabular}{llcl} 
No & \multicolumn{1}{c}{ Parameter } & Satuan & Alat/ Metode \\
& Parameter fisika & & \\
1 & Suhu & ${ }^{\circ} \mathrm{C}$ & Multitester \\
2 & Kedalaman & $\mathrm{m}$ & Meteran \\
3 & Salinitas & $\mathrm{ppt}$ & Refraktometer \\
4 & Kekeruhan & $\mathrm{NTU}$ & Turbidymeter \\
5 & Kecepatan Arus & $\mathrm{m} / \mathrm{s}$ & Botol, tali, stopwatch \\
6 & Pasang surut & $\mathrm{m}$ & Data sekunder \\
1 & Parameter kimia & & \\
2 & pH & & pH meter \\
\hline
\end{tabular}

\subsubsection{Pengambilan Sampel Kuda Laut (Hippocampus sp.)}

Sampel kuda laut (Hippocampus sp.) dilakukan pengamatan menggunakan transek dengan luasan transek $5 \times 5 \mathrm{~m}$. Identifikasi jenis Hippocampus sp. menggunakan Fish Identification: Find Species (http://www.fishbase.org/identification/ SpeciesList. php? genus= Hippocampus).

\subsubsection{Pengambilan Sampel Copepoda}

Sampel diambil menggunakan metode statis yaitu dengan menggunakan ember yang bervolume $10 \mathrm{~L}$ dengan $10 \mathrm{kali}$ pengulangan dan disaring menggunakan plankton net. Setelah disaring dan mendapat volume tersaring sebanyak 300 $\mathrm{mL}$, sampel lalu diberi larutan lugol 10\%.

\subsection{Analisis Data}

Kepadatan masing-masing jenis pada setiap lokasi sampling dihitung dengan menggunakan rumus Odum (1971) sebagai berikut:

$$
D i=\frac{n i}{A}
$$

Keterangan:

Di $\quad=$ Kepadatan jenis $\left(\right.$ ind $\left./ \mathrm{m}^{2}\right)\left(\mathrm{Ind} / \mathrm{Ha} ; 1 \mathrm{Ha}=10.000 \mathrm{~m}^{2}\right)$

ni $\quad=$ Jumlah total individu jenis (individu)

A = Luas daerah yang disampling $\left(\mathrm{m}^{2}\right)$

Perhitungan kelimpahan zooplankton dengan metode dianalisis menggunakan rumus Sachlan (1982):

Keterangan:

$$
N=\frac{1}{A} \times \frac{B}{C} \times n
$$

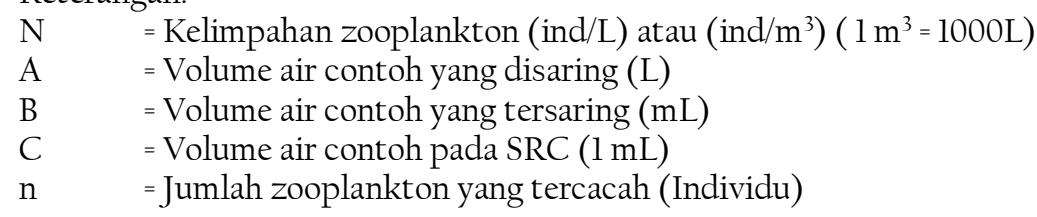

\section{Hubungan Copepoda terhadap Keberadaan Hippocampus sp.}

Analisis data hubungan copepoda sebagai indikator keberadaan Hippocampus sp. sebelumnya menggunakan analisis regresi. Namun, setelah dilakukan uji normalitas data yang dihasilkan tidak normal yaitu nilai analisis melebihi 0,05. Nilai suatu data dikatakan normal jika nilai yang terdistribusi normal harus lebih kecil dari 0,05 atau sama dengan 0,05. Oleh karena itu penulis menggantikan analisis menggunakan analisis komponen utama Principal Component Analysis (PCA), hal ini dilakukan untuk menghilangkan korelasi antara variable bebas melalui transformasi variabel bebas asal ke variabel baru yang tidak berkorelasi sama sekali (Ifadah, 2011).

\section{HASIL DAN PEMBAHASAN}

\subsection{Kondisi Kualitas Air di Perairan Desa Sebong Pereh}

Kondisi kualitas air yang dinilai melalui parameter fisika kimia perairan memiliki peranan penting bagi kuda laut (Hippocampus sp.) dan copepoda untuk kelangsungan hidupnya. Adapun kondisi kualitas air di Perairan Sebong Pereh disajikan pada Tabel 2. 
Tabel 2. Kondisi kualitas air di Perairan Desa Sebong Pereh

\begin{tabular}{cllccc} 
No & \multicolumn{1}{c}{ Parameter } & Satuan & $\begin{array}{c}\text { Nilai } \\
\text { Rata-rata }\end{array}$ & $\begin{array}{c}\text { Baku Mutu } \\
\text { Perairan }\end{array}$ \\
\hline 1 & Fisika & Suhu & ${ }^{\circ} \mathrm{C}$ & $30,7 \pm 0,46$ & Alami, Coral 28-30 \\
2 & & Salinitas & $0 \%$ & $33,0 \pm 0,20$ & Alami, Coral 33-34 \\
3 & & Kedalaman & $\mathrm{cm}$ & $133,4 \pm 31,08$ & $<5$ \\
4 & & Kekeruhan & $\mathrm{NTU}$ & $3,9 \pm 0,33$ & \\
5 & & Kecepatan Arus & $\mathrm{m} / \mathrm{s}$ & $0,2 \pm 0,03$ & $7-8,5$ \\
6 & & Pasang surut tertinggi & $\mathrm{m}$ & $1,0 \pm 0,58$ & $>58$ \\
7 & & Pasang surut terendah & & $7,6 \pm 0,08$ & $8,1 \pm 0,07$ \\
\hline
\end{tabular}

* Keputusan Menteri Lingkungan Hidup No 51 tahun 2004 tentang Baku Mutu Air Laut untuk Biota Laut.

Suhu merupakan salah satu faktor yang berpengaruh di perairan dan bagi biota laut. Suhu yang didapatkan pada Perairan Desa Sebong Pereh menunjukkan nilai rata-rata $30,7 \pm 0,46^{\circ} \mathrm{C}$ yang sesuai dengan baku mutu perairan Kepmen LH No.51 Tahun 2004. Pengambilan parameter suhu dilakukan dengan keadaan cuaca cerah. Kisaran suhu yang dianggap baik bagi suatu perairan dan layak bagi kelangsungan hidup organisme yaitu dengan nilai suhu $27-32^{\circ} \mathrm{C}$, peningkatan suhu akan mempengaruhi laju reaksi kimia dan metabolisme (Nontji, 2008). Suhu normal untuk keberlangsungan kuda laut yaitu rentang $20-30^{\circ} \mathrm{C}$ (Syafiuddin et al., 2008). Pada penelitian Syafiuddin et al., (2008) pada suhu $32^{\circ} \mathrm{C}$ induk kuda laut membutuhkan energi yang semakin besar karena aktivitasnya yang semakin meningkat.

Hasil pengukuran salinitas di Perairan Desa Sebong Pereh didapati salinitas dengan nilai rata-rata 33,0 0 0,20 \%o. Nilai salinitas yang didapatkan di perairan Desa Sebong Pereh sesuai dengan baku mutu perairan berdasarkan Kepmen LH No.5l tahun 2004. Kuda laut bersifat euryhaline sehingga dapat beradaptasi pada perairan yang cukup luas yaitu memiliki kemampuan untuk menyesuaikan diri pada lingkungan dengan pada kisaran salinitas maksimum 30-32 \%o (Syafiuddin et al., 2008). Menurut Asmara (2005), salinitas optimal bagi plankton adalah antara 20-35 \%o.

Hasil pengukuran kedalaman di Perairan Desa Sebong Pereh didapatkan kedalaman perairan dengan nilai rata-rata $133,4 \pm 31,08 \mathrm{~cm}$. Pengukuran dilakukan pada saat air laut sedang surut. Hal ini dilakukan untuk mempermudah pengambilan sampel kuda laut saat penelitian.

Hasil pengukuran kekeruhan di Perairan Sebong Pereh yang dilakukan secara exsitu didapatkan nilai rata-rata 3,9 $\pm 0,33$ NTU. Nilai kekeruhan yang didapatkan dari perairan Desa Sebong Pereh sesuai dengan nilai baku mutu perairan berdasarkan Kepmen LH No.5l tahun 2004.

Hasil pengukuran arus di Perairan Sebong Pereh yang dilakukan secara insitu didapatkan nilai rata-rata 0,2 $\pm 0,03$ m/s. Arus yang didapatkan memiliki nilai yang kecil dan mencirikan arus pada Perairan Desa Sebong Pereh tidak kuat. Pengaruh angin dan pasang surut sangat menentukan besar dan arah arus secara horizontal. Sementara keadaan topografi sangat menentukan arah arus vertikal (Mustikasari et al., 2015).

Hasil pengukuran pasang surut pada perairan Desa Sebong Pereh diperoleh dari data sekunder LANTAMAL IV Tanjungpinang Kepri bagian Kabupaten Bintan, khususnya daerah Tanjung Uban dengan melihat nilai dari pasang tertinggi dan surut terendah. Pasang tertinggi dengan nilai rata-rata 2,5 $\pm 0,58 \mathrm{~m}$ dan nilai pasang surut dengan nilai ratarata $1,0 \pm 0,58 \mathrm{~m}$. Ketinggian pasang dalam satu periode terjadi satu kali. Tipe surut seperti ini disebut diurnal dimana dalam 24 jam hanya terjadi satu kali surut dan satu kali pasang (Surinati, 2007; Lestari et al., 2015).

Hasil pengukuran $\mathrm{pH}$ di Perairan Desa Sebong Pereh didapatkan nilai rata-rata 7,6 $\pm 0,08$. Nilai pH yang didapatkan dari perairan Desa Sebong Pereh sesuai dengan baku mutu perairan berdasarkan Kepmen LH No.51 tahun 2004. Pertumbuhan serta kelangsungan kehidupan biota akuatik sangat dipengaruhi oleh derajat keasaman (Effendi, 2003)

Hasil pengukuran DO di Perairan Desa Sebong Pereh didapatkan kedalaman dengan nilai rata-rata 8,1 $\pm 0,07 \mathrm{mg} / \mathrm{L}$. Nilai DO yang didapatkan dari Perairan Desa Sebong Pereh sesuai dengan baku mutu perairan berdasarkan Kepmen LH No.5l tahun 2004. Kuda laut bisa beradaptasi pada perairan yang cukup luas untuk menyesuaikan dirinya terhadap perairan kuda laut harus memiliki kadar oksigen $>3 \mathrm{mg} / \mathrm{L}$ (Syafiuddin et al., 2008).

\subsection{Kepadatan Hippocampus sp. di Perairan Desa Sebong Pereh}

Hasil pengamatan kuda laut di Perairan Desa Sebong Pereh ditemukan tiga jenis kuda laut (Hippocampus sp). Jenis dan kepadatan laut di Perairan Desa Sebong Pereh disajikan pada Tabel 3.

Tabel 3. Jenis dan kepadatan Hippocampus sp. di Perairan Desa Sebong Pereh

\begin{tabular}{ccc} 
No & Jenis Kuda Laut & Kepadatan (ind/Ha) \\
1 & Hippocampus comes & 670 \\
2 & Hippocampus kuda & 530 \\
3 & Hippocampus mohnikei & 400 \\
\hline
\end{tabular}

Hasil dari pengamatan Hippocampus sp. yang ditunjukkan pada Tabel 3. Jenis yang ditemukan paling banyak yaitu dari spesies H. comes dengan kepadatan 670 ind/Ha, kemudian H. kuda dengan kepadatan 530 ind/Ha dan paling sedikit yaitu H. mohnikei dengan kepadatan 400 ind/Ha. Pada penelitian Rabiansyah et al. (2015), yang dilakukan pada Perairan 
Desa Sebong Pereh kepadatan Hippocampus sp. yang paling tinggi yaitu dari spesies H. spinosissimus dengan nilai kepadatan $0,0073 \mathrm{ind} / \mathrm{m}^{2}$ (73 ind/Ha). Penelitian ini dilakukan pada bulan Mei, menurut (Lourie et al. 2004) kuda laut jenis $\mathrm{H}$. spinossimus puncak kehadirannya yaitu pada bulan Mei hingga Oktober.

\subsection{Kelimpahan Copepoda di Perairan Desa Sebong Pereh}

Hasil pengamatan dari pencacahan Copepoda di perairan Desa Sebong Pereh ditemukan 8 jenis Copepoda. Jenis dan kelimpahan Copepoda di Perairan Desa Sebong Pereh disajikkan pada Tabel 4.

Tabel 4. Jenis dan kelimpahan Copepoda di Perairan Desa Sebong Pereh

\begin{tabular}{cllc} 
No & \multicolumn{1}{c}{ Ordo } & \multicolumn{1}{c}{ Spesies Copepoda } & Kelimpahan Copepoda (ind $\left./ \mathrm{m}^{3}\right)$ \\
1 & Calanoida & Nauplii sp. & 3380 \\
2 & & Acartia sp. & 1450 \\
3 & & Acrocalanus sp. & 480 \\
4 & & Lucicutia sp. & 6100 \\
5 & Cyclopoida & Calanus sp. & 1450 \\
6 & & Oithona sp. & 680 \\
7 & Harpacticoida & Tisbe sp. & 4450 \\
8 & & Microsetella sp. & 870 \\
\hline
\end{tabular}

Berdasarkan Tabel 8. Pada perairan Sebong Pereh ditemukan tiga ordo pada sub kelas Copepoda yaitu Calanoida, Cyclopoida dan Harpacticoida. Kelimpahan yang paling banyak ditemukan yaitu pada jenis Lucicutia sp. dari ordo Calanoida dengan kelimpahan $6.100 \mathrm{ind} / \mathrm{m}^{3}$ dan paling sedikit ditemukan jenis spesies Acrocalanus sp. dengan kelimpahan $480 \mathrm{ind} / \mathrm{m}^{3}$. Proporsi Copepoda terbesar yang terdapat pada Perairan Sebong Pereh yaitu pada ordo Calanoida dan yang terendah dari ordo Cyclopoida. Hal ini menunjukkan jenis dari ordo Calanoida melimpah pada Perairan Desa Sebong Pereh. Jenis Copepoda dari ordo Calanoida ini selalu mendominasi setiap titik dan setiap kedalaman perairan (Nugraha \& Hismayasari, 2011).

\subsection{Hubungan Kelimpahan Copepoda Terhadap Kepadatan Hippocampus sp.}

Analisis data dilakukan dengan melihat hubungan copepoda terhadap keberadaan kuda laut (Hippocampus sp.), serta kaitannya dengan faktor lingkungan. Hasil analisis data ditunjukkan pada Gambar 2.

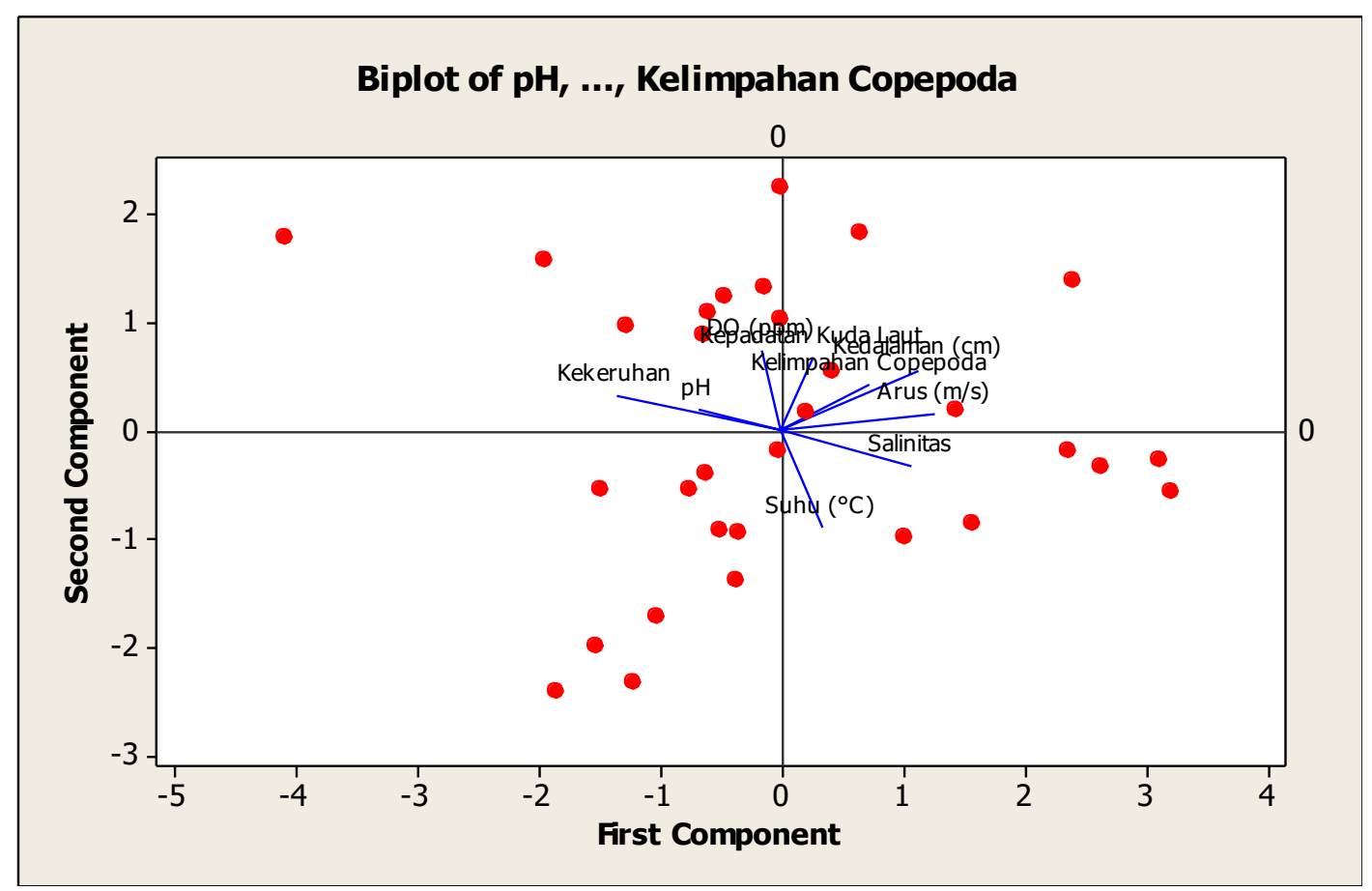

Gambar 2. Analisis Principal Component Analysis (PCA)

Berdasarkan hasil analisis data yang ditunjukkan pada Gambar 2., menunjukkan kepadatan kuda laut dan kelimpahan copepoda tidak memiliki kedekatan, parameter yang memiliki kedekatan terhadap kuda laut yaitu DO dan kedalaman. Titik yang memiliki kedekatan pada kepadatan kuda laut, DO, dan kedalaman yaitu pada titik 11, 14, 25, 29, 
dan 30. Pada titik 9 yang kuat berpengaruh yaitu kelimpahan copepoda. Pada titik 7 yang kuat mempengaruhi pada perairan tersebut yaitu parameter salinitas dan suhu. Parameter kecepatan arus memberi pengaruh besar pada titik 4.

Pada analisis yang terdapat pada titik 11, 14, 25, 29 Hippocampus sp. dengan parameter DO memiliki kedekatan dan memberi pengaruh. Kuda laut dapat beradaptasi pada perairan yang cukup luas, dengan nilai DO $>3 \mathrm{mg} / \mathrm{l}$ (Syafiuddin et al., 2008). Pada titik yang sama antara Hippocampus sp. dan kedalaman memiliki keterkaitan saling berpengaruh. Kuda laut umumnya hidup di perairan dangkal hingga pada kedalaman $30 \mathrm{~m}$ dan tergantung pada jenis yang beradaptasi (Saraswati \& Pebriani, 2016; Syafiuddin et al., 2008).

Berdasarkan hasil pengamatan diketahui bahwa tidak ditemukan hubungan antara kelimpahan copepoda dengan Hippocampus sp. di Perairan Desa Sebong Pereh. Akan tetapi, terdapat hasil pendugaan di lapangan dan informasi yang diperoleh dari nelayan, kuda laut di Perairan Desa Sebong Pereh umumnya ditemukan pada daerah yang terdapat pada makroalga coklat (Sargassum sp.). Berdasarkan hasil penelitian Ulfah et al. (2018), nelayan biasanya menangkap kuda laut di sekitar makroalga coklat (Sargassum sp.), rumput laut ini disebut "rengkam" oleh masyarakat sekitar Desa Sebong Pereh. Pada penelitian Asmanelli dan Andreas (1993), juga menyebutkan bahwa tempat kuda laut untuk merekat umumnya pada rumput laut coklat, agar kuda laut dapat berkamuflase yaitu menyesuaikan diri terhadap tempat tinggalnya. Oleh karena itu, diduga keberadaan kuda laut di perairan Desa Sebong Pereh dipengaruhi oleh keberadaan rumput laut coklat (Sargassum sp.).

\section{SIMPULAN}

Kelimpahan copepoda tidak memiliki hubungan terhadap kepadatan kuda laut (Hippocampus sp.)di Perairan Desa Sebong Pereh. Hal ini menunjukkan copepoda tidak bisa dijadikan sepenuhnya sebagai indikator keberadaan kuda laut (Hippocampus sp.) di Perairan Desa Sebong Pereh.

\section{UCAPAN TERIMA KASIH}

Penulis mengucapkan terima kasih kepada pihak-pihak yang telah membantu proses penelitian ini, diantaraya Kepala Desa Sebong Pereh, Sekretaris Desa Sebong Pereh, Ketua POKMASWAS Desa Sebong Pereh, dan Ibu Fitria Ulfah, S.P., M.M.

\section{REFERENSI}

Asmara, A. (2005). Hubungan Struktur Komunitas Plankton Dengan Kondisi Fisika-Kimia Perairan Pulau Pramuka dan Pulau Panggang, Kepulauan Seribu. Institut Pertanian Bogor.

Asmanelli \& Andreas, I.P. (1993). Beberapa Catatan Mengenai Kuda Laut dan Kemungkinan Pengembangannya. Oseana, 18(4): 145151.

Effendi, H. (2003). Telaah Kualitas Air Bagi Pengelolaan Sumberdaya dan Lingkungan Perairan. Kanisius. Yogyakarta. 257p.

Fianda, C., Pratomo, A., \& Idris, F. (2015). Identifikasi dan inventarisasi Jenis Kuda Laut (Hippocampus sp.) yang Hidup di Perairan Pulau Bintan Provinsi Kepulauan Riau. Repository UMRAH.

Ifadah, A. (2011). Analisis Metode Principal Component Analysis (Komponen Utama) dan Regresi Ridge dalam Mengatasi Dampak Multikolinearitas dalam Analisis Regresi Linear Berganda. Universitas Negeri Semarang.

Kurniawan, D. (2014). Kajian Laju Pertumbuhan Tahunan dan Distribusi Karang Goniopora stokesi (Milne Edwards and Haime, 1851) di Perairan Pulau Laelae Dan Pulau Barranglompo. Universitas Hasanuddin.

Lestari, F., Damar, A., Soewadi, K., \& Adrianto, L. (2015). Fluks Nitrogen Anorganik Terlarut di Perairan Pesisir Kota Tanjungpinang, Propinsi Kepulauan Riau. Jurnal Segara, 10(1): 51-59.

Lourie S. A., Foster, S.J., Cooper, E.W.T., \& Vincent, A.C.J. (2004). A Guide to the Identification of Seahorses. Project Seahorse and TRAFFIC North America. University of British Columbia and World Wildlife Fund. North America. 120p.

Mustikasari, E., Dewi, L.C., Heriati, A., \& Pranomo, W.S. (2015). Pemodelan Pola Arus Barotropik Musiman 3 Dimensi (3D) Untuk Mensimulasikan Fenomena Upwelling di Perairan Indonesia. Jurnal Segara, 11(3): 25-35.

Nontji, A. (2008). Plankton Laut. LIPI Press. Jakarta. 331p.

Nybakken, J.W. (1988). Biologi Laut. PT. Gramedia Pustaka Utama. Jakarta. 459p.

Nugraha, M.F.I., \& Hismayasari, I.B. (2011). Copepoda: Sumbu Kelangsungan Biota Akuatik dan Kontribusinya Untuk Akuakultur. Media Akuakultur, 6(1): 13-20.

Odum, E.P. (1993). Dasar-dasar Ekologi. UGM Press. Yogyakarta. 697p.

Rabiansyah., Pratomo.,A., \& Irawan., H. (2015). Studi Ekologi Kuda Laut (Hippocampus) di Perairan Desa Sebong Pereh Kecamatan Teluk Sebong Kabupaten Bintan. Repository UMRAH.

Redjeki, S. (2007). Pemberian Copepoda Tunggal dan Kombinasi Sebagai Pakan Alami Kuda Laut (Hippocampus Kuda). Ilmu Kelautan, 12(1): 1-5.

Sachlan, M. (1982). Planktonologi. Fakultas Peternakan dan Perikanan. Universitas Diponegoro, Semarang. 117p.

Saraswati,S.A., \& Pebriani, D.A.A. (2016). Monitoring Populasi Kuda Laut di Perairan Pantai Padang Bai Karangasem Bali. Samakia: Jurnal Ilmu Perikanan, 7(2): 100-105.

Surinati, D. (2007). Pasang Surut dan Energinya. Oseana, 32(1): 15-20.

Syafiuddin, M., Zairin, J.R., Jusadi, D., Charman, O., Affandi, R., Trijuno, D.D., \& Mutmainna. (2008). Pengaruh Suhu Terhadap Perkembangan Ovari Kuda Laut (Hippocampus barbouri) dalam Wadah Budidaya. Torani : Journal of Fisheries and Marine Science, 18(1):81-86.

Ulfah, F., Afrizal, \& Pratomo, A. (2018). Sustainability of Seahorses: Lesson Learned of Local Wisdom From Bintan Island, Riau Island Province. E3S Web of Conferences, 47(7): 001-009. 